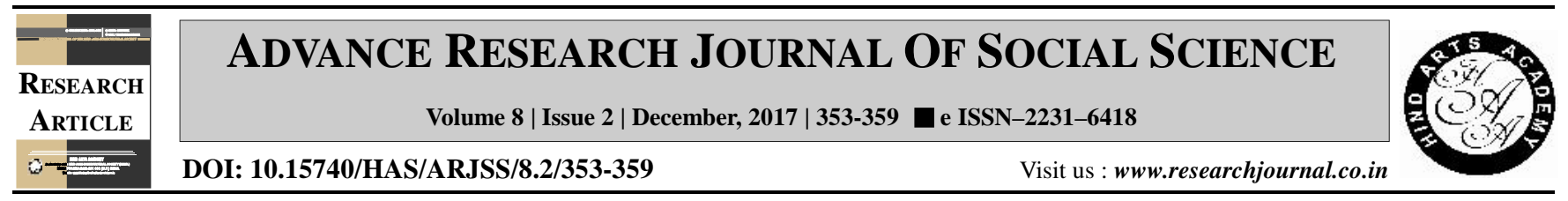

\title{
Parents' attitude towards girls' education: A scale to measuring the attitude of the parents
}

Uzma Kalam* and Banwari Lal ${ }^{1}$

Jamia Millia Islamia, NEW DELHI (INDIA)

${ }^{1}$ Department of Extension Education, College of Agriculture (Agriculture University), JODHPUR (RAJASTHAN) INDIA

(Email: aujubls@gmail.com)

\section{ARTICLE INFO :}

$\begin{array}{lll}\text { Received } & : & 27.05 .2017 \\ \text { Revised } & : & 09.11 .2017 \\ \text { Accepted } & : & 21.11 .2017\end{array}$

\section{KEY WORDS :}

Attitude of parents, Tool to measures attitude towards girl's education

HOW TO CITE THIS ARTICLE : Kalam, Uzma and Lal, Banwari (2017). Parents' attitude towards girls' education: A scale to measuring the attitude of the parents. Adv. Res. J. Soc. Sci., 8 (2) : 353359, DOI: 10.15740/HAS/ARJSS/8.2/ 353-359.

*Author for correspondence

\begin{abstract}
The growth of any country is depends on the education level of the women because the major work of the agriculture is completing by the rural women therefore if we want to change the national development than we have to change our attitude towards women education.The study was conducted in the Noida city in the state of Uttar Pradesh. based on development of reliable and valid scale for measuring parents' attitude towards girls' education. The 100 statements were formulated for the scale from different sources such as books, journals, experts, opinion of parents and researchers etc. and after editing 74 were selected after content validity was considered for this took the help from 50 experts. The respondents were taken from 8 groups and the were collected by quota and purposive sampling techniques from 160 respondents and used the Likert's methods of summated ratings for analysis.Final selection of the statements was based on the $t$ value. Total 66 statements were arranged in descending order according to the $t$ value. These 66 selected statements obtained value in the range of 10.75 to 0.29 ; total 25 statements were selected with highest t values with the range of 10.75 to 3.98 .
\end{abstract}

